\title{
From blurred to sharp: setting the standards for more pragmatic land use planning at the local level in Lao PDR
}

\author{
Bourgoin, J. ${ }^{1,2}$ and D. Pullar ${ }^{1}$ \\ ${ }^{1}$ School of Geography, Planning and Environmental Management, University of Queensland (UQ), Brisbane \\ ${ }^{2} \mathrm{CATCH}-U p$ Program (Comprehensive Analysis of Trajectories of Changes in the Uplands), Institut de \\ Recherche pour le Développement (IRD, France) and Centre for International Forestry Research (CIFOR, \\ Indonesia), at the National Agriculture and Forestry Research Institute (NAFRI, Lao PDR), Vientiane \\ Email:.j.bourgoin1@uq.edu.au
}

\begin{abstract}
For the last two decades, since the Rio Conference on Environment and Development, land-use planning (LUP) has been carrying the hopes of providing a concrete instrument to translate sustainable development discourses into practice. In the Lao PDR, it is being seen as a way to provide alternatives to swidden agriculture and more recently, as an instrument to Reduce Emissions from Deforestation and forest Degradation (REDD). However, when assessing the impact of past LUP, many observers have noted the discrepancy between good intentions, as displayed in policy and project documents, and actual implementation due to the limited capacity of local institutions (Lestrelin et al., 2011a). Overcoming such a problem requires an objective analysis of its extent and its potential negative consequences. To avoid blind trust in delusive success stories, evaluation methods assessing the quality of the LUP process (i.e. level of community participation and understanding of LUP activities by local stakeholders) have been designed (Lestrelin et al., 2011b). From the perspective of developing a country-wide monitoring system for participatory land use planning (PLUP), this paper addresses two main research questions:

- How to assess the quality of a PLUP output, i.e. measuring the gap between principles and practice in PLUP?

- What can be done to increase the credibility, and therefore the practicality and feasibility, of the proposed land use plans?

By analysing land zoning outputs from past and recent PLUP this paper underlines the irrationality of village LUP maps which often appear inconsistent with the principles of land use policies. In general the management of rural landscapes in the uplands of Lao PDR is difficult to grasp due to a tacit agreement between villagers willing to minimize land taxes and district authority lacking proper human and financial resources.

Acknowledging the gap between the declared agricultural land from household surveys and what can be observed from satellite or village land use maps, the paper proposes a new approach to increase planning realism while reinforcing local participation in the PLUP process. An innovative participatory platform involving local communities in learning the complexities of LUP through a role-play was proposed by Bourgoin and Castella (2011). The authors argued that a landscape simulation exercise can help disclose the landscape management and livelihood strategies of different stakeholders at different scales.

Building on this knowledge, this paper describes a negotiation platform allowing villagers discuss land zoning and management practices. Adaptive and accessible, the method is assisted by a participatory 3D model combined with a village socio-economic and geographic information system providing feedback about cost/benefit associated with each land use plan. Through successive iterations, villagers gradually refine their plans by exploring land use change scenarios.

Beside its contribution to enhanced participation in landscape planning, the proposed method, which was successfully tested in six study villages of Viengkham District, can support the introduction of innovative land use systems in the northern uplands of Lao PDR. Furthermore, this instrument can be used to certify land use plans and provide a standard procedure for PLUP implementation.
\end{abstract}

Keywords: Participatory land use planning, landscape simulation, certification, role playing, Lao PDR 


\section{INTRODUCTION}

The emergence of participatory approaches as cornerstone of development and management programs is linked with the wide recognition of drawbacks from "intrusive land management strategies" (Agrawal and Gibson, 1999:630) and the compelling requirements to recognize the values of local perception and knowledge (Chambers, 1983, Hage et al., 2010, Agrawal, 1995). Integration of local complexity and priorities facilitating adoption and implementation through empowerment processes were the general claims of intrinsic benefits underlying community-based initiatives (Neef and Neubert, 2010).

Participatory Land-Use Planning (PLUP) has emerged as an alternative to conventional mapping, involving local communities and stakeholders in management processes that will condition their well-being. Bearing the hopes of the international community, land use planning was perceived as way to translate global development discourses into efficient sustainable resource management (FAO, 1993). Avoiding top-down usage as an instrument of power to enforce specific land policies (Rydin, 1995), PLUP is supposed to guarantee the involvement of local stakeholders in decision-making supported by efficient visual and negotiation-support instruments (Bourgoin et al. 2011). The appeal of this methodology has attracted the attention of many developing countries like Lao PDR, the case study in this article. After repeated unsuccessful attempts to address development and resource management concerns through land-use planning (LUP) projects (Lestrelin et al., 2011a), the Lao government recently enacted PLUP as a national priority. Although training on technological tools (e.g. GPS, GIS, satellite imagery) will be provided to implementers, the tight schedule imposed nationally to apply PLUP in the whole country by 2015 is raising many questions regarding the value of such a process in terms of participation, as quantity seems to be favoured over quality. Further, it may confirm the opinion of certain participatory GIS detractors disparaging the use of information and communication technology in resource management (Chambers, 2006). Hypothetically, in line with the government strategy to foster economic growth and leave the 'least developed country' category by 2020, this zoning attempt could well serve the interests of agri-businesses seeking for land for concessions and de facto legitimize a 'land grab'. To avoid detrimental drifts from original PLUP principles, certain means need to be framed to ensure the integrity of the process. In a recent paper, Lestrelin et al. (2011b) highlighted the importance to define objective criteria to gauge the participatory nature of a process rather than presuming it. Similarly, this article focuses on the importance to analyse PLUP outputs in a coherent framework. Two research questions are thus addressed: i): "How to assess the quality of a PLUP output and visualize the gap between principles and their local translation?" and ii) "What can be done to fill the gap and evolve from blurred to sharp land use plans?"

\section{PROJECT OVERVIEW}

In 2009-2010, the Centre for International Forestry Research (CIFOR) participated in an action-research project on land-use planning in collaboration with Lao partners from national (National Agriculture and Forestry Research Institute - NAFRI), provincial (Provincial Agriculture and Forestry Offices - PAFO) and district (District Agriculture and Forestry Offices and Land Management Authority - DAFO and DLMA) institutions. Under this project, the method proposed here was designed and applied in the six villages of Muangmuay cluster in the district of Viengkham (Luang Prabang province; Figure 1).

\section{TOWARDS A NEGOTIATION SUPPORT PLATFORM}

To address knowledge gaps and assist village zoning activities, a negotiation support system was designed, combining both socioeconomic and geographic information into an accessible and participatory modelling platform.

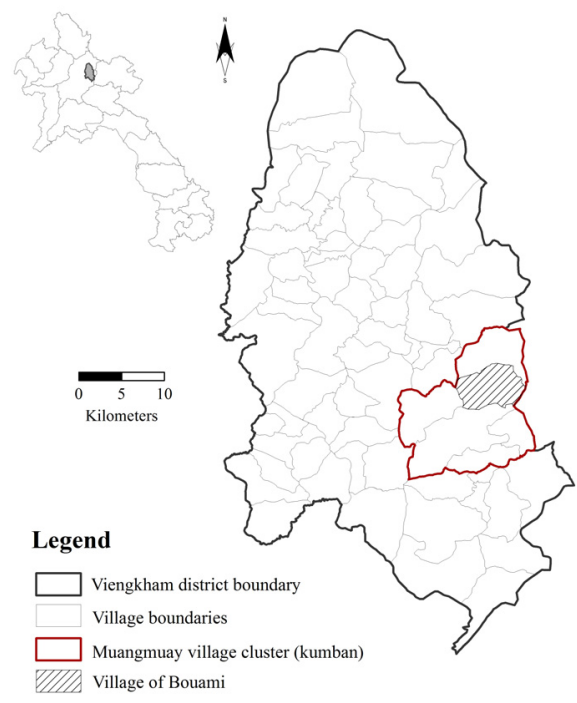

Figure 1. Location of the study area

Socio-economic information: A stratified random sampling of 30 households was conducted in all six villages. By encompassing all classes of poverty (low, medium, high), the survey aimed at capturing the composition of villagers' annual income and clarify the link between landscape and local livelihoods. The socio-economic data collection was further used to build a specific village typology representing how four household types share 
financial and spatial resources differently and therefore how different household strategies will have distinctive impacts on land uses. Household types are defined according to their degree of dependence from a particular sector of activity.

Geographic information: In order to facilitate a broad comprehension during zoning activities, a threedimensional physical model gave a common ground for people with different backgrounds and experiences to learn and negotiate (Rambaldi and Callosa-Tarr, 2002). Using pins and yarn of different colours, village members delineated zones on the 3D model, debating the location and size of each land use within a 10 year timeframe. When a plan covering the whole village area is achieved, the data is captured and entered in a geographic information system (GIS). As the landscape is a not a flat surface, radial displacement is deflected by taking a series of perpendicular photos above the 3D model in order to minimize loss of data and errors associated with geo-referencing (Rambaldi and Callosa-Tarr, 2002). The images are stored in computers and imported in geographic software (open-source Quantum GIS or commercial ArcGIS). The different land uses are captured using 'on-screen' digitizing and converted into vector layers. GIS scripts operate the surface calculation of each zone within the village boundary (in hectares) and store the information in the layer's attribute table.

Integration in a model: The combination of geographic and socio-economic data is achieved through the use of a model designed with spreadsheet programming to build a simple application that can be manipulated by nonexperts. The program is compatible with Microsoft Excel or Open Office (open source) and displays a clear user interface. Developed as a research tool, the product's aim is to be distributed in its final version to Laotian endusers in their language (i.e. researchers and/or district/province government staff).

The purpose of the model is to simulate the human requirements to exploit a proposed village land use plan in relation with technological and physical conditions defined by the user. It has been designed in such a way that by nature it does not impinge on either participation or discussions between actors, proposing ballpark figures that can be easily understood and manipulated (Bourgoin et al., 2011). Approximations and shortcomings are part of this negotiation-support tool which computes levels of acquaintance between land-use plans and current village situation. The notion of planning credibility is introduced to gauge the feasibility of a land-use plan.

Practically, all information gathered during interviews is formatted to fit the spreadsheet model. For instance, the percentage of each household type is combined with their corresponding share of income from agricultural activities, livestock and non-timber forest products. The entry point for integrating village data and geographic information is the area of each land use as villagers are involved in many activities related to the exploitation of the landscape. In each village, the data analysis provides information on how much the household types depend on each sector of financial activity. With the area of each land use obtained from the land use plan, the model links geographic data with the level of reliance and the expected income per hectare for each household type in a particular village.

The integration of those multiple parameters with spatial arrangements of the landscape is made by several equations taking the following form:

(1) $\mathrm{I}_{\mathrm{x}}=\sum_{i=1}^{n} \sum_{j=1}^{m}\left(S_{x i} \cdot A_{j} \cdot R_{i}\right)$

where $I_{x}$ is the income attributed to the household group $x$, having $i$ activities on $j$ land uses. $S_{x i}$ is the share of activity $i$ in the total income of the household type $x . A_{j}$ is the area of land use $j$ and $R_{i}$ is the return on activity $i$.

The $\mathrm{n}$ activities include rotational and permanent agriculture, collection of Non-Timber Forest Products (NTFPs) and Livestock. The return value associated to these activities is expressed in kips/hectare (with US $\$ 1=8031.5$ kips). As livestock cannot be represented spatially, the return estimate, $\mathrm{R}_{\text {livestock }}$ is described in equation 2.

(2) $\mathrm{R}_{\text {livestock }}=\frac{K_{j} \cdot p}{f}$

where $\mathrm{K}_{\mathrm{j}}$ is the livestock carrying capacity for each land use (head of cattle/ha), $\mathrm{p}$ is the average price of one head of cattle and $\mathrm{f}$ is the livestock selling frequency (in years).

The total income corresponding to a single activity $\mathrm{i}$ is thus:

(3) $\mathrm{I}_{\mathrm{i}}=\sum_{x=1}^{y} I_{x i}$ 
The off-farm income cannot be assessed spatially but it depends on the village status and wealth. In order to have an adaptive value for this activity, $\mathrm{k}$ is defined as a constant share of the income generated by the agricultural activities (4).

(4) $\mathrm{I}_{\text {off-farm }}=k \cdot \sum_{i=1}^{n} I_{i}$

In an extensive system like the uplands of Laos, the limiting factor to exploitation is not the land scarcity but the availability of labour. The credibility of a plan is evaluated by the ratio between the labour force predicted by the model and the labour force available in the village. The estimated labour force needed to exploit the proposed land-use plan can be calculated as shown in equation 5:

(5) $\mathrm{LF}_{\mathrm{plan}}=\sum_{j=1}^{m}\left(A_{j} \cdot C C_{j}\right)$

where the labour force (LF) is directly related to the carrying capacity (CC) or labour per hectare.

Future village labour force can be extrapolated from the population growth information. While hypothesizing that the proportion of labour force remains constant in the total population, the population growth factor is also used as a labour force growth factor.

The model also estimates environmental values of the landscape with biodiversity and carbon quotes. This scoring system is defined by the land use type and was previously introduced in a simulation on zoning by Bourgoin and Castella (2011).

By nature, this model can be used as a diagnostic tool to analyse the legitimacy of former land use plans. Retrospective analysis can thus estimate the value of the land use plans conducted by the district agriculture and forestry officers in the past. The model can integrate the areas of each land use along with socio-economic data of the village at the time. For the village of Bouami (Figure 1), it is then estimated that the current labour force can only exploit $29 \%$ of the landscape. Illustrating poor local consultation, this result also highlights the low considerations to integrate village socio-economic information in the design of land use plans.

\section{RATIONALIZING THE PROCESS FOR IMPROVED OUTPUTS AND OUTCOMES}

\subsection{Ensuring data quality}

In the first place, the simulation can be perceived as a learning tool, providing feedback during the zoning activity and ultimately allowing villagers to realize how census data collected every year by district staff to inform aggregated statistics at the provincial level, could be used to support their village LUP. The village of Bouami illustrates a process that has been conducted with similar results in all six villages of the target village cluster or kumban. The population of this village is decreasing with an annual rate of $1.5 \%$ in average. The labour force evaluated at 112 people in 2010 is then evaluated at 104 in 2015. A first zoning iteration computed in the model gives an estimation of 461 labour force units needed to exploit the plan. Under similar technological inputs (e.g. no fertilizers, no tractors), the credibility of the plan is evaluated at $23 \%$ meaning that only this percentage of the agricultural land could be exploited by the future village labour force. At this point, two kinds of drawbacks are intertwined: first, the villagers tend to over-estimate the extent of agricultural areas to prevent shortages. Second, the data provided during village and household surveys might be

\begin{tabular}{|c|c|c|c|}
\hline & $\begin{array}{c}\text { Village } \\
\text { census }\end{array}$ & $\begin{array}{c}\text { In-depth } \\
\text { survey of 30 } \\
\text { households }\end{array}$ & $\begin{array}{c}\text { Update } \\
\text { during } \\
\text { PLUP }\end{array}$ \\
\hline $\begin{array}{c}\text { Average } \\
\text { areas of } \\
\text { upland } \\
\text { rice per } \\
\text { household } \\
\text { hectares) }\end{array}$ & 5 ha & 3 ha & 7.3 ha \\
\hline $\begin{array}{c}\text { Village } \\
\text { Labor } \\
\text { force }\end{array}$ & 112 & 136 & 192 \\
\hline
\end{tabular}
inaccurate.

Table 1. Agriculture information for Bouami from different sources 


\begin{tabular}{|l|r|r|r|r|}
\hline & Plan 1 & Plan 3 & Plan 5 & Plan 7 \\
\hline Land use efficiency (\%) & 23 & 51 & 85 & 89 \\
\hline Land uses (hectares) & \multicolumn{5}{|l|}{} \\
\hline Conservation forests & 1242.3 & 1185.7 & 1185.7 & 1185.7 \\
\hline Grass land & 272.8 & 373.0 & 373.0 & 373.0 \\
\hline Permanent crops & 194.2 & 57.4 & 30.7 & 30.7 \\
\hline Plantation NTFPs & 0 & 87.0 & 87.0 & 87.0 \\
\hline Production forest & 307.2 & 414.7 & 414.7 & 414.7 \\
\hline Rotational crops & 1145.9 & 921.8 & 875.5 & 847.0 \\
\hline Plantation trees & 107.1 & 156.9 & 183.7 & 183.7 \\
\hline Reserve land & 77.46 & 150.3 & 196.6 & 225.0 \\
\hline
\end{tabular}

Table 2. Evolution of the land use through PLUP iterations

After acknowledging the results, the villagers decided that the plan was not optimal and inspected the raw survey data used in the model. After going through the socio-economic census, the villagers conceded that the data was inaccurate and made available updated values for labour force, agricultural areas and fallow length. Table 1 shows that the census data seem to underestimate shifting-cultivation areas while villagers provide numbers that would satisfy government recommendations. Villagers admit that they usually give wrong figures to avoid paying taxes that are calculated on the basis of labour force and area under shifting cultivation.

During the second iteration, the participants also rectified a previous assertion by the advising that the whole landscape cannot be fully exploited.

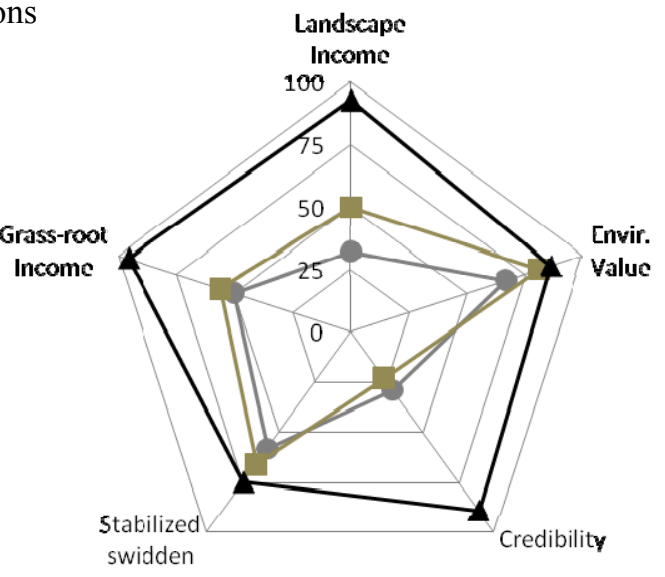

-LUP $2006-$ PLUP - plan $1 \rightarrow$ PLUP - plan 7

Figure 2. Comparison of successive land use plans

With the physical terrain obviously represented on the 3D model, the group estimated the fraction of area (in percent) that could be effectively used for agricultural purposes.

\subsection{Ensuring zoning process quality}

At the end of the process, seven iterations were necessary to reach consensus within the group. Table 2 displays the gradual refinement of landscape plans with four key steps representing significant changes. A constant diminution of rotational crops can be observed while the diversification of agricultural activities is enhanced throughout the process. At first, villagers tend to over-estimate their capacity to exploit large areas of swidden agriculture and fields of permanent crops. In another technological situation, the excessive demand for labour force could be compensated by the intensification of land exploitation with mechanization and/or the use of chemical inputs. The decrease of traditional agriculture is followed by the establishment of teak plantations that represents long-term investments with low labour force requirements. Village production forests, from which villagers can collect firewood, wildlife and NTFPs, are also established to the detriment of old fallows. For plans 5 to 7, clarifications are made by acknowledging that all the agricultural land cannot be utilized by the village and that certain parts of it are classified under reserve, put on hold for the next generations or immigrants. Working in a prospective manner allows villagers to design credible land-use plans, representative of the current village situation. The results of the model can be summarized with key indicators derived from the calculations and therefore create a comparative framework. Landscape Income relates to the level of income generated by the whole range of land uses in the village while Grass-root Income refers to the financial returns for households 
mostly dependent on shifting cultivation and NTFP collection. Presented as ratios, their value is related to the maximum income value generated by a landscape exploited with optimal efficiency (by the whole village for the first one and by the type A for the second indicator). The third of these indicators measures the plan's environmental value which combines biodiversity and carbon scoring systems. The fourth indicator, referred to as stabilized swidden, relates to the share of landscape non-occupied by swidden agriculture and refers to the Government's forest strategy (GoL, 2005). The last indicator measures the credibility of the land use plans.

Notwithstanding the increase in credibility through the successive planning iterations, the process is also characterized by improved values for all the other parameters (Figure 2). Indicators related to the landscape structure such as environmental value and stabilized swidden do not display drastic changes due to the fiveyear time-frame scenario planning. However, under short-term perspectives, the economic values of the landscape and the grass-root income experience obvious improvements. When comparing the evolution of LUP in Bouami, it can be observed that the resulting plan obtained from LUP in 2006 is reaching similar values as the first iteration of PLUP in 2010 (Figure 2). Here, the

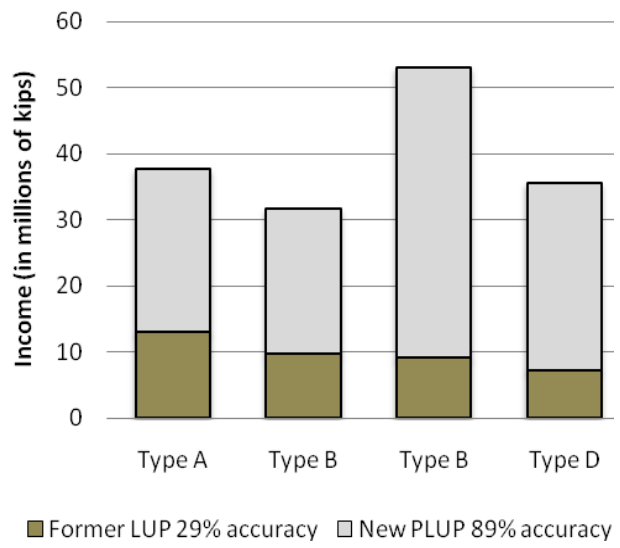

Figure 3. Difference in income for different household types successive iterations allow the villagers to conceive a plan more closely related to their own situation. Additionally, the model assists in visualizing the impact of both land use planning approaches on the livelihood of the different groups of households within the village: Figure 3 displays the levels of income of the different household types for each resulting plan. Characterized by efforts towards local participation, PLUP outcomes, in addition to being precise at $89 \%$, provide in average $64 \%$ more income than the past LUP approaches.

\section{DISCUSSION AND CONCLUSIONS}

The method developed here satisfies the requirement proposed by Bourgoin et al. (2011) in terms of PLUP principles. By allowing feedback of simple but relevant indicators, villagers are empowered with means to negotiate land use plans. From what has been experienced in the field, local communities seem at first quite suspicious when outsiders (foreigners and/or Lao governmental staff) survey their village and seem reluctant to deliver accurate information about the land management. An iterative zoning process is proposed here as a way to gradually comfort the villagers with the aims and objectives of PLUP and to highlight the link between spatial land-use organization and the village socio-economic context. Trust building through participatory activities seems to provide better quality inputs that will fundamentally "lead to higher quality decisions" (Reed 2008:2420). Beyond developing a relevant methodology to PLUP, the paper also presents a way to rationalize the process of PLUP itself. As demonstrated for the village of Bouami, the framework that combines socioeconomic and spatial information in a GIS could be used as a certification scheme. Developed in the uplands of Laos, the methodology is relevant for places in relative isolation from markets and technical innovations although the rationale and GIS tools developed could be used in other contexts of land-use planning.

Blind appreciation of artificial planning has been already criticized by Lestrelin et al. (2011) who advocate that an objective assessment of participation is likely to monitor the level of achievement of a project that would otherwise automatically entitle itself "participatory". In a similar fashion, the physical output, represented as a map, has to be appraised to gauge the ability of such a plan to describe local desires on potential development. For once in the process of land use planning, successive media allow villagers to design a rational plan they want to develop in their village in a near future. In this case study, the model's purpose was to answer particular questions at an appropriate scale. Holistic models and integrative simulations would not have provided more insights on local land uses as they find their robustness constrained by a few unreliable parameters such as the local census data. With an analytical perspective, this instrument could prove efficient in discriminating between credible and sterile representations of landscape land use plans. In fact, it seems crucial to assess if the planning activity can enable the plans to be reasonably applied for the sake of improving local livelihoods. Many concerns have been raised in the research community in Laos concerning the forthcoming elaboration of village PLUP at 
the national scale. Under high political pressure, the National Land Management Authority (NLMA), under the Prime Minister's Office has the mandate to perform PLUP in the 47 poorest districts of Laos by 2011 and cover the whole country by 2015 . With limited time allocated per village, untrained district implementers are likely to repeat the same drawbacks observed in the past and currently from pilot projects. This article advocates that $a$ posteriori analysis of a LUP is possible while providing support to government staff to use such a method as a PLUP routine. Currently, staff members from the district land management authority and department of forestry and agriculture are being trained to replicate this method at the scale of the district of Viengkham.

Assessing the 'quality' of a land use plan should become a standard procedure along with the measurement of participation because the development of 'sharp' plans conditions the usefulness of land-use planning projects and unveils the complexity of landscape mosaics beyond the bounds of traditionally delusive success stories.

\section{REFERENCES}

Agrawal, A. (1995). Dismantling the divide between indigenous and scientific knowledge. Development and Change, 26, 413-439.

Agrawal, A. and C. Gibson (1999). "Enchantment and disenchantment: the role of community in natural resource conservation." World development 27: 629-649.

Bourgoin, J. \& Castella, J.-C. (2011). 'PLUP FICTION': landscape simulation for participatory land use planning in Northern Lao PDR. Mountain Research and Development, 31, 78-88.

Bourgoin, J., Castella, J.-C., Pullar, D. V., Lestrelin, G. \& Bouahom, B. (2011). 'Tips and tricks' of participatory land use planning in Lao PDR: Towards a land zoning negotiation support platform. Conference on Earth System Governance, 17-20 May 2011. Colorado State University, Colorado, USA.

Chambers, R. (1983). Rural development: Putting the last first, New York: Longman.

Chambers, R. (2006). Participatory mapping and geographic information systems: Whose map? Who is empowered and who disempowered? Who gains and who loses? The Electronic Journal of Information Systems in Developing Countries, 25, 1-11.

FAO (1993). Guidelines for land-use planning. Food and Agriculture Organization of the United Nations. Rome. GOL (2005). Forestry Strategy to the year 2020. In: GOVERNMENT OF LAOS, V. (ed.).

Hage, M., Leroy, P. \& Petersen, A. C. (2010). Stakeholder participation in environmental knowledge production. Futures, 42, 254-264.

Lestrelin, G., Castella, J.-C. \& Bourgoin, J. (2011a). Territorialising sustainable development: policy and practices of land-use planning in the Lao PDR. Journal of Contemporary Asia, In Press.

Lestrelin, G., Bourgoin, J., Bouahom, B. \& Castella, J.-C. (2011b). Measuring participation: Case studies on village land-use planning in northern Lao PDR. Applied Geography, 31, 950-958.

Neef, A. \& Neubert, D. (2010). Stakeholder participation in agricultural research project: a conceptual framework for reflection and decision-making. Agriculture and Human Values.

Rambaldi, G. \& Callosa-Tarr, J. (2002). Participatory 3-Dimentional Modelling: Guiding Principles and Applications. ASEAN Regional Centre for Biodiversity Conservation (ARCBC), Los Baños, Philippines.

Reed, M. S. 2008. Stakeholder participation for environmental management: A literature review. Biological Conservation, 141, 2417-2431.

Rydin, Y. 1995. Sustainable development and the role of land use planning. Area, 27, 369-377.

Selener, D. 1997. Participatory action research and social change, Ithca, NY: Cornell University Press. 